\title{
Perceptions of early adolescent African-American girls concerning virginity and romantic relationships
}

\author{
This article was published in the following Dove Press journal: \\ Nursing: Research and Reviews \\ 24 October 2012 \\ Number of times this article has been viewed
}

\section{Gwendolyn D Childs \\ Reashanda White \\ Connie Hataway \\ Linda Moneyham \\ Vanessa Gaioso}

University of Alabama at Birmingham, School of Nursing, Birmingham, AL, USA
Correspondence: Gwendolyn D Childs 1720 2nd Avenue South, NB 444,

Birmingham, AL 35294-1210, USA

Tel +l 2059964687

Fax + I 2059967183

Email gchilds@uab.edu
Background: Nationally, African-American girls aged 15-19 years have a higher incidence of Chlamydia, gonorrhea, and syphilis compared with White and Hispanic girls in the same age group. To address this epidemic of sexually transmitted infection, it is imperative to target African-American girls during early adolescence and before sexual debut. According to the 2011 National Youth Risk Behavior Survey, approximately 7\% of African-American girls initiate sex prior to the age of 13 years. The purpose of this descriptive qualitative study was to explore the perceptions of African-American girls aged 12-14 years about virginity and relationships, and how their perceptions influence their decision to engage in or abstain from sexual activity.

Methods: A convenience sample of 64 participants was recruited from community organizations in Alabama. Data were collected using individual interviews and focus groups. Individual interviews focused on values and beliefs about being a virgin, choosing boyfriends, and perceptions about good and bad relationships. Focus groups were held to validate findings from the individual interviews. Verbatim transcripts of audiotapes, observation notes, and demographic data were used as the primary data for analysis. Content analysis was used and interpretation of qualitative data to formulate meaningful categories, themes, and patterns. Qualitative research software (QSR N-Vivo ${ }^{\circledR}$ ) was used to code and sort data into categories.

Results: The mean age of the study sample was 12.9 years. Of 64 participants, five reported having engaged in sexual activity. The mean age of sexual debut was 13 years. Common themes that emerged included respecting oneself, the ideal boyfriend, and characteristics of a romantic relationship.

Conclusion: Findings from this study suggest that the sexually transmitted infection prevention programs should build upon values related to virginity to delay sexual activity. Furthermore, the findings suggest a need for education about healthy relationships.

Keywords: sexual decision-making, sexual risk-taking, sexually transmitted infections, boyfriends

\section{Introduction}

Romantic relationships are described as "mutually acknowledged ongoing voluntary interactions [having] a distinctive intensity, commonly marked by expressions of affection and current or anticipated sexual behavior". ${ }^{1}$ It is believed that the development of romantic relationships begins during early adolescence and evolves throughout adolescence into adulthood. ${ }^{2}$ Within the context of romantic relationships, adolescents formulate their own understandings of sexual behavior and sexuality. ${ }^{3}$ Findings from the National Longitudinal Study of Adolescent Health indicate that the majority of 
adolescents have had at least one relationship with a boy or girl by the end of early adolescence. ${ }^{1,4}$

Early adolescence, defined as age $12-14$ years, is a period of transition that involves pubertal and cognitive changes as well as changes in social development signifying the beginning of sexual maturity and adulthood..$^{5-7}$ A major developmental task during adolescence is development of identity. Among adolescent girls, development of identity is often associated with intimacy, which they perceive to be intertwined with caring and affection. Caring is a highly valued feeling among early adolescent girls and plays a major role in becoming involved in a romantic relationship. ${ }^{8,9}$ It is through involvement in romantic relationships and the degree of importance placed on caring that early adolescent girls are likely to engage in coital and noncoital behaviors. ${ }^{1,9}$ Findings from a study of adolescent relationships showed that perceived high levels of intimacy, caring, and emotional engagement within a relationship are significantly associated with initiating sexual activity. ${ }^{10}$

A study using data from the National Longitudinal Study of Adolescent Health examined the development of romantic relationships from early adolescence to early adulthood. Findings from that study showed that African-American adolescents were less likely to be involved in a romantic relationship compared with Caucasian adolescents. However, if African-American adolescents, particularly girls, were involved in romantic relationships, they were more likely to be involved in long-term relationships rather than multiple short-term relationships. ${ }^{4}$ Because the likelihood of engaging in sexual intercourse increases with duration of a relationship, Meier and Allen ${ }^{4}$ suggest a possible association between involvement in long-term romantic relationships and early sexual debut among African-American adolescents.

According to the 2011 National Youth Risk Behavior Survey, approximately 7\% of African-American females engage in sexual activity prior to the age of 13 years. ${ }^{11}$ Despite this small percentage, early initiation of sexual activity is associated with multiple sexual risk-taking behaviors, such as inconsistent condom use and a high number of lifetime sexual partners. Both these behaviors are associated with increased risk of unplanned teenage pregnancy and contracting a sexually transmitted infection, including human immunodeficiency virus (HIV). ${ }^{12-14}$ Nationally, African-American girls aged 15-19 years have a higher incidence of Chlamydia, gonorrhea, and primary and secondary syphilis compared with White and Hispanic females of the same age group. ${ }^{15}$ To address this epidemic of sexually transmitted infections, it is imperative to target African-American girls during early adolescence and before initiation of sexual activity.

Much has been written about sexually active adolescents in terms of predictors of sexual debut, sexual risk behaviors, and progression from being a virgin to becoming sexually active. However, there is a dearth of literature about early adolescent African-American girls' understanding of virginity and how this interplays with decisions about engaging in sexual activity. Further, little is known about their perception of personal qualities in boyfriends and relationships, and how their perceptions of these lead to involvement in romantic relationships. The purpose of this qualitative study was to identify developmental and sociocontextual factors that influence decision-making processes about sexual activity in African-American girls aged 12-14 years. The data reported in this article focus on exploration of their perceptions about virginity and romantic relationships, and how these perceptions influence their decision to engage in or abstain from sexual activity.

\section{Materials and methods Design, setting, and sample}

This study used the qualitative approach of descriptive inquiry ${ }^{16}$ within the context of individual interviews and focus groups to generate detailed descriptions of early adolescent girls' perceptions about virginity, boyfriends, and relationships. The descriptive inquiry approach allows the researcher to look closely at the data with the intent of providing detailed analysis of the participants' stories without losing the meanings of the participants' words and descriptions of experiences. In doing so, the findings are presented within the context of reality as perceived by the participants. ${ }^{16}$ The descriptive inquiry approach was well suited to this study, in that the data as presented by the study participants could be used to describe perceptions about being a virgin and beliefs associated with maintaining virginity, characteristics believed to be important when choosing a boyfriend, psychosocial and situational factors that influence the ability to delay initiation of sexual activity, and perceptions about factors constituting good and bad relationships.

Between August 2010 and February 2012, a convenience sample of 64 African-American adolescent girls was recruited from community-based organizations affiliated with an HIV Prevention Network Group located in a metropolitan city in the southeastern United States. The HIV Prevention Network Group is a consortium of clinics and community-based organizations, the focus of which is 
to educate communities about risk factors and modes of transmission for sexually transmitted infections, including HIV, through community outreach programs and implementation of curriculum-based education on sexually transmitted infections, including HIV, in the area high school setting. Some of the participating community-based organizations and groups affiliated with the HIV Prevention Network include Girls Inc, local African-American sororities, and the Young Women's Christian Association. These community-based organizations were identified as initial recruitment sites because they have established ongoing activities for adolescents, ranging from afterschool programs and summer camps to community educational events on health, teenage pregnancy, and prevention of HIV and other sexually transmitted infections. Potential participants were also recruited by "word of mouth" via participants already enrolled in the study. Criteria for inclusion were being an African-American girl, age 12-14 years, ability to read and speak English, willingness to participate in an individual interview or group discussion, parental/guardian consent to participate, and adolescent assent to participate.

\section{Procedures}

The institutional review board of the University of Alabama at Birmingham reviewed and approved the protocol for this study. A combination of purposive and snowball (referral) sampling was used to recruit study participants. A total of 70 adolescent girls were screened: three girls were not enrolled because they were under the age of 12 years and a further three girls were not enrolled because they were unable to schedule an interview time. For the eligible 64 girls, parental/guardian consent and adolescent assent were obtained prior to enrolment in the study. Each participant taking part in an individual interview or a focus group discussion received $\$ 40$ cash as compensation for participation in the study.

\section{Demographic data and sexual behavior}

A demographic form was used to elicit information about age, educational level, grades achieved, socioeconomic status (based on whether the participant received a free or low-cost school lunch), ${ }^{17}$ marital status of parents, guardianship (lives with parent or someone else), number of siblings, birth order, and if ever had sex. A separate form was used to elicit information about sexual behavior, which included initiation of sexual activity, age of sexual debut, number of sexual partners in past year, and condom use. For each item related to sexual behavior, participants were asked about vaginal, oral, and anal sex.

\section{Individual interviews}

Face-to-face individual interviews were conducted first and focused on values and beliefs about being a virgin, choosing boyfriends, and perceptions about good and bad relationships. The interviews were conducted by a member of the research team trained in interviewing skills and techniques and interview protocol. All interviews were held in a private room at a location convenient for the participant. The interviews were conducted using a semistructured interview guide developed by the principal author, which served as the protocol for all interviews to ensure consistency in implementation. The following questions were included in the interview guide: "What does being a virgin mean to you?", "Imagine a boy wants you to be his girlfriend. Tell me some things about him that would persuade you to be his girlfriend?", and "Describe what you think is a good relationship between a boyfriend and girlfriend, and describe a bad relationship." The interviewer used probing questions as needed to elicit further descriptions of participants' experiences and perceptions. Each interview was digitally recorded and transcribed verbatim. Thirty-six participants took part in the individual interviews, which lasted 45-60 minutes.

\section{Focus groups}

After the individual interviews were completed, recruitment was started for three focus group sessions, which were held to validate the findings of the individual interviews. These sessions were conducted by the principal author and another member of the research team. Twenty-eight participants took part in each focus group discussion with 9-10 participants per group. The focus groups were conducted using a focus group implementation guide developed by the principal author, which served as the protocol for each focus group. The questions and scenarios for this guide were developed based on findings from the individual interviews. All focus group sessions were held in a private conference room at a location convenient for the participants. After introductions and before the focus group discussion began, the interviewer shared with the participants an overview of the perceptions and thoughts of the girls who participated in the individual interviews. The participants in the focus group were then invited to comment on the findings. An example of a question included in the guide is: "The girls we interviewed said being a virgin meant respecting your body and loving yourself; tell me what you think about these comments. Tell me your thoughts about what being a virgin means to you." This format of questioning permitted discussion about choosing boyfriends and describing good and bad relationships between boyfriends 
and girlfriends. Additional questions were used to elicit further feedback from the group. All focus group sessions were digitally recorded and transcribed verbatim. The focus group sessions lasted 90-180 minutes.

\section{Data analysis}

Transcribed interviews and focus group sessions were reviewed by the author and compared with the digital recordings to ensure accuracy of the transcripts. Qualitative content analysis was used to interpret the qualitative data because it is the analysis strategy of choice for qualitative descriptive studies. ${ }^{16}$ The authors independently read each interview and focus group transcript and extracted data segments which were organized according to the interview questions. Next, each author independently coded and categorized the data segments, then formulated meaningful categories, themes, and patterns. The final coding was determined by agreement between at least two of the three coders. Qualitative research software (QSR N-Vivo ${ }^{\circledR}$ ) was used to code and sort the data into categories.

The validity and reliability of the findings were assessed by: independent review and analysis of transcripts by the authors, with differences in coding resolved through discussion; use of focus groups to solicit feedback on the plausibility of findings from individual interviews; and comparison of findings with those reported in the published literature to determine consistency of results.

\section{Results}

\section{Sample characteristics}

The participants ranged in age from 12-14 (mean 12.9 \pm 0.84 ) years. The majority of participants lived in single-parent households headed by their mother, father, grandmother, or other relative $(n=42,65.6 \%)$. All participants living in single-parent households reported that their fathers were actively involved in their lives (Table 1). Of the 64 participants, only five (7.8\%) reported having engaged in oral, anal, and/or vaginal sex. The age of initiation of oral sex was 14 years $(n=1)$ and for anal sex was 13 years $(n=1)$. All five sexually active participants (100\%) reported engaging in vaginal sex, with the mean age of initiation being $13 \pm 1$ years. Two of the sexually active participants (40\%) reported having engaged in one or more types of sexual activity (vaginal, anal, and/or oral). Four sexually active participants (80\%) reported having had more than one sexual partner during the year prior to enrollment in the study. All sexually active participants reported inconsistent condom use during oral, anal, and/or vaginal sex.

\section{Findings from interviews}

Content analysis yielded three themes that embodied the participants' perceptions about virginity, boyfriends, and relationships, ie, "respecting myself", "ideal boyfriend", and "characteristics of a romantic relationship". The first theme, "respecting myself", was related to maintaining virginity. The majority of participants held strong beliefs about the importance of being a virgin and waiting until they were older to have sex. The major sources of these beliefs identified by participants were conversations with their mothers and teachings in their churches. The second theme, "ideal boyfriend", involved those physical and personality characteristics that the participants wanted in a boyfriend. The third theme, "characteristics of a relationship", was related to the participants' understandings and beliefs about boyfriendgirlfriend relationships in terms of what constituted a good versus bad relationship. The second and third themes emerged from discussions about people and situations that would influence the participants' abilities to maintain their virginity.

\section{Respecting myself theme}

In discussing sexually-related topics with girls, it is important to know how they define sexual activity. Therefore, the girls were asked what sex is. The majority of girls defined sex as being oral, anal, and vaginal. One girl described sex as "like mouth to penis, mouth to vagina, penis to vagina, penis to butt, all that". However, several girls in one of the focus groups were unaware that engaging in oral and anal sex constituted sexual intercourse. One girl stated: "Because a lot of the girls, they probably don't even know what it [oral sex] is. And they talk about it. And when you say like, finger [sex], they probably don't think it's something. 'Cause it [oral and finger sex] ain't sex until like his penis put in her." Another girl added, "they [friends] said they half virgin. I know what they are saying, they saying like, he ain't actually put it [penis] in her."

In regards to anal sex, one girl in the focus group stated "the one they stick it [penis] in your butt. I don't even think they know that [anal sex] is sex." Another girl explained, "Because you don't have that greater chance of getting pregnant."

These type of statements were not made by girls who participated in the individual interviews or other focus groups. After a discussion about what sex is, the girls in this focus group understood that sex included oral, anal, and vaginal sex, regardless of the risk for becoming pregnant.

To gain an understanding of how the girls defined virginity, they were asked what a virgin is. All of the girls said 
Table I Sociodemographics of individual interview participants and focus group participants

\begin{tabular}{|c|c|c|c|c|c|c|}
\hline \multirow[t]{2}{*}{ Characteristics } & \multicolumn{2}{|c|}{$\begin{array}{l}\text { Individual interview } \\
(n=36)\end{array}$} & \multicolumn{2}{|c|}{$\begin{array}{l}\text { Focus group } \\
(n=28)\end{array}$} & \multicolumn{2}{|c|}{$\begin{array}{l}\text { Total } \\
(n=64)\end{array}$} \\
\hline & $\mathbf{n}$ & $\%$ & $\mathbf{n}$ & $\%$ & $\mathbf{n}$ & $\%$ \\
\hline \multicolumn{7}{|l|}{ Age (years) } \\
\hline 12 & 15 & 41.7 & 10 & 35.7 & 25 & 39 \\
\hline 13 & 5 & 13.9 & 14 & 50 & 19 & 29.7 \\
\hline 14 & 16 & 44.4 & 4 & 14.3 & 20 & 31.3 \\
\hline \multicolumn{7}{|l|}{ Grade level } \\
\hline 6th & 4 & II.I & 4 & 14.3 & 8 & 12.5 \\
\hline 7th & 11 & 30.6 & 8 & 28.6 & 19 & 29.7 \\
\hline 8th & 7 & 19.4 & 12 & 42.9 & 19 & 29.7 \\
\hline 9th & 14 & 38.9 & 4 & 14.3 & 18 & 28.1 \\
\hline \multicolumn{7}{|l|}{ Free or low-cost school lunch } \\
\hline Yes & 20 & 55.6 & 17 & 60.7 & 37 & 57.8 \\
\hline No & 16 & 44.4 & 11 & 39.3 & 27 & 42.2 \\
\hline \multicolumn{7}{|l|}{ Family structure } \\
\hline Lives with mother and father & 13 & 36.1 & 7 & 25 & 20 & 31.3 \\
\hline Lives with mother and stepfather & 2 & 5.6 & 0 & 0 & 2 & 3.1 \\
\hline Lives with mother & 15 & 41.6 & 14 & 50 & 29 & 45.3 \\
\hline Lives with father & 3 & 8.3 & 2 & 7.1 & 5 & 7.8 \\
\hline Lives with grandmother & 1 & 2.8 & 3 & 10.7 & 4 & 6.2 \\
\hline Lives with other relative & 2 & 5.6 & 2 & 7.1 & 4 & 6.2 \\
\hline \multicolumn{7}{|l|}{ Ever had sex } \\
\hline Yes & 3 & 8.3 & 2 & 7.1 & 5 & 7.8 \\
\hline No & 33 & 91.7 & 26 & 92.9 & 59 & 92.2 \\
\hline \multicolumn{7}{|c|}{ Number of sexual partners in past year* } \\
\hline \multicolumn{7}{|l|}{ Oral sex } \\
\hline 2 or more partners & 1 & - & 0 & - & I & - \\
\hline \multicolumn{7}{|l|}{ Anal sex } \\
\hline 2 or more partners & 1 & - & 0 & - & I & - \\
\hline \multicolumn{7}{|l|}{ Vaginal-penile sex } \\
\hline One partner & 1 & - & 0 & - & I & - \\
\hline 2 or more partners & 2 & - & 2 & - & 4 & - \\
\hline \multicolumn{7}{|l|}{ Condom use* } \\
\hline \multicolumn{7}{|l|}{ During oral sex } \\
\hline Never & 1 & - & 0 & - & I & - \\
\hline \multicolumn{7}{|l|}{ During anal sex } \\
\hline Never & 1 & - & 0 & - & I & - \\
\hline \multicolumn{7}{|l|}{ During vaginal-penile sex } \\
\hline Never & 1 & - & 0 & - & I & - \\
\hline Sometimes & 0 & - & I & - & I & - \\
\hline Always & 2 & - & I & - & 3 & - \\
\hline
\end{tabular}

Notes: *Some participants are represented in more than one category of sexual activity. Therefore, the numbers may not total the number for "ever had sex".

that it was someone who "has not had sex yet." Several girls added, "A virgin is like, when you ain't had oral sex or nothing like that." Another girl referred to it as "staying pure". Being a virgin was highly valued by the majority of girls. One girl stated, “It's [virginity] sacred, you don't just want to go around doing it with everybody". As each girl talked about what being a virgin meant to them, they shared stories of what their mothers told them about being a virgin. In one of the individual interviews, a girl told the interviewer that her mother had said "you ought to keep your virginity, because it's precious, once you lose it you don't get another one".
Many of the girls talked about how their mothers encouraged them to wait until they were older and to "wait for the right person".

The value placed on virginity as heard throughout the individual interviews was validated in the focus groups. One girl in the group stated, "being a virgin means having respect for my body and not just giving myself away". Another girl stated, "it's not right for, like, you to give up your virginity for something that doesn't quite make sense at all". This girl went on to share a story about her friend: 
"You can't just be going like having sex with your boyfriend and stuff like that, 'cause like, my friend, perfect example, she had sex and then like a couple of weeks later they broke up. And then she's no longer a virgin and he's gone."

Other girls in the individual interviews and focus groups shared similar stories about their friends who were sexually active. In one of the focus group sessions, a girl talked about the "power" of virginity. She stated: "Your virginity is your dignity. So, when you give away your virginity, that's like giving away a part of yourself. I feel like if you still have your virginity, not saying that the girls that do not have their virginity are dumb, but, you have all the power in the world if you still got your virginity and you are confident with yourself."

The sense of power and confidence in relation to virginity seemed to be a sentiment held by all the girls. However, because the virginity status of the girls in the individual interviews and focus groups was not disclosed publicly, it is unknown whether the five girls who had engaged in sexual activity felt less powerful or less confident in themselves than did the girls who are virgins. Because the girls placed a high value on virginity, they were asked what would make it difficult for them to wait until they were older to have sex. All of the girls agreed that having a boyfriend would make it difficult to wait. One girl stated: "Sometimes they [boyfriends] don't want to wait and it's like they'll ask you and sometimes you might be curious of how things go and you might just decide to try it." Similar responses were given by other girls who participated in the individual interviews and focus groups.

\section{Ideal boyfriend theme}

Finding the "right" boyfriend was mentioned by all of the girls. A girl in one of the focus groups said "sometimes it's not like what they look like on the outside." This opinion was echoed by girls who participated in individual interviews and focus groups. When asked what they looked for in a boyfriend, the girls immediately began identifying personality traits and behavior: "I think you should choose a boyfriend on like how much do ya'll have in common and is he like, well I guess the looks do matter, they matter to me, and after looks, is he truly a good boy ... he won't pressure you into nothing that you won't do and he'll be a gentleman and stuff. Like, and if he have a little bit of bad in him, ahh that's all right."

Another girl added, "they act respectable and they act like a gentleman towards you and towards other people. Like they can't just be respectful around you but they have to be respectful to everybody and around everybody." Several girls stated that a boyfriend had to be "funny, outgoing, street smart and book smart". One girl added that he has to be "a person that cares about what you think about". In one of the focus groups, a girl noted that character is important; however, it is not the first thing a person notices. She said: "I understand about their character but, the first you look at, you don't look at his character [it's] not on the outside. It's on the inside. So you looking at his appearance first ... if he look you know decent and cute enough then the way he talks to you ... that gives a hint of his character, of his talk and all of that." Another girl added, "if I see a fine boy, or something like that, I'm going to like him".

Having good looks was an important feature identified by all of the girls in the individual interviews and focus groups. In addition to character and physical appearance, overall impression, academic achievement, and future goals were also important factors for a boyfriend to possess. One girl stated: "He has to be sweet and funny, very intelligent. A deep personality, like um poetry or something or have goals in his life too. I don't want a guy who just slacky. I don't want someone whose pants are hangin' down to their ankles. I don't want a gang banger for a boyfriend. I want an intelligent person who can be a CEO if he wanted, write a book, make songs, or something." One girl in the group added, "I'm sorry, I'm that person like if you don't make A's and B's or you don't make higher grades than me, I'm sorry I can't date you". A boyfriend who earned good grades in school was important to all girls in the study. All of the girls indicated that they were not willing to date a boy who was not doing well in school.

In terms of a boy's reputation, none of the girls wanted to date a boy who had a bad reputation: "his reputation matters, no negative reputation." One girl described a bad reputation as "he had sex with this girl, had sex with that girl and everybody know". The majority of girls did not feel it was important to date the most popular boy in school. A girl in one of the focus groups stated "you can be a geek for all I care, you can be a sports star, or just average - it really doesn't matter". Similar statements were made by other girls in the individual interviews and focus groups.

\section{Characteristics of a romantic relationship theme}

Although the majority of girls in the study did not have boyfriends, all of them had ideas about what constituted a good versus bad relationship. Most of their opinions were based on their observations of relationships involving their friends and relatives. There were no shared stories concerning relationship behaviors observed between the girls' mothers and fathers/boyfriends. 
The general consensus was that in a good relationship there must be trust between boyfriend and girlfriend. This was highlighted by the following statement: "When you and a boy got trust. Like you can tell him something. He's like your best, best, best friend. You can tell him anything in the world." The underlying themes of the discussion about trust were friendship and respect. One girl explained:

"I think a good relationship starts off as friends because if you can't even be friends you definitely can't even be in a relationship. Friends first, because when you even look at the word it's boy friend not boy relationship. It's boy friend. You have to start off being friends first. I feel like a good relationship has respect and trust always, and honesty because without honesty there's nothing. Without trust there's nothing.” Another girl added: “... y'all can talk about anything, just get on the phone and talk for hours about anything. He can sit there and talk to you about what's on his mind, you can sit there and talk to him and y'all just have a good connection."

Several girls talked about how in a good relationship a boyfriend will respect his girlfriend's decision not to have sex: "He can wait 'til you ready to have sex. He treats you good, don't cheat on you." Another girl added, "he don't like you just for your body and how you look, he like you for your inside and it's okay if he like your body. But he truly likes you from the inside too." The girls also equated respect with how a boy treats his girlfriend. The majority of girls believed a sign of a good relationship is that the boyfriend "treats you well and he doesn't treat you like trash". One of the girls elaborated on the statement "treats you well" by stating "a good boyfriend don't put his hands on you, don't curse or call you another word".

In contrast, girls participating in one of the focus groups believed that a good relationship is when the boyfriend and girlfriend argue. One of the girls in the group explained: "Some of us folks like arguing and fighting with their boyfriends. Like, I mean, everybody don't want the perfect guy that's just gonna sit there, 'Oh, I love you', all that stuff, everything nice. Sometimes you want a little excitement, you know. I don't like dudes that don't fuss back. You know, I want somebody that's going to fuss back with me, or something. You know ... it's annoying when they don't fuss back." All of the girls in the group smiled and nodded positively in response to the statement. One of the girls added, "To me when you fuss with a boy somehow it just make you love them more". This was the only group of girls in the study who considered "arguing and fighting with their boyfriends" to be a sign of a good relationship.
Several girls identified bad relationships as being characterized by “when you can't trust each other". Given that the girls identified trust as key to a good relationship, it was no surprise that they believed not having trust constituted a bad relationship. In addition to lack of trust, being pressured by your boyfriend to do things that you do not want to do was discussed in relationship to having sex. One girl explained, "all they [boys] care about is you and your body and don't care about you, what you think or anything ... all he wants every minute and every second is to talk about sex". Similar statements arose during multiple interviews and focus groups. All of the girls believed that being pressured to have sex was indicative of a bad relationship.

Couples who "break up constantly but then get back together" were described by one girl as a bad relationship. The girls shared various reasons why couples break up; however, the most common reason described by the girls was "fighting or arguing for no reason at all, just over little bitty simple stuff". With the exception of the one focus group who considered arguing to be good for a relationship, the other girls believed constant arguing was a sign of a bad relationship. The majority of girls felt that a boyfriend and girlfriend should make each other happy and have fun. This sentiment was explained by another girl:

“... if he can't even put a smile on your face that's a bad relationship. If he can't pull you out of a bad mood, that's a bad relationship. If he makes your mood worse that's a bad relationship. I know relationships have their ups and downs but when it's just constant and it's just not getting better, that's a bad relationship. If it's not even moving forward, if it's just like at a standstill it can't even be a relationship. It's like you just calling each other boyfriend and girlfriend for no reason."

Furthermore, several girls talked about relationships where the boyfriend and girlfriend were not supportive or respectful of each other. One girl explained it as "they discourage each other, are awful and never have anything good to say about that person. He's always cussing at [her] or vice versa." Similar comments about respecting each other were made during the individual interviews as well as the focus group sessions.

As the girls discussed what they perceived to constitute bad relationships, they shared stories about relationships involving their friends or relatives. It appeared that their observations of those relationships helped to shape their opinions about the quality of relationships. This was evident as one girl in a focus group shared a story about her friend: "She goes with a boy and he wanted her to [have sex with] 
him and he was like do my friends too. I think it's wrong. Because if that's your girlfriend why would you want her to do all your ... That ain't love at all."

Another girl shared a story about her cousin who had been in an abusive relationship: “... my cousin, she was in like an abusive relationship. Because like they knew each other for two years and then they got married and then like she said, after they got married he was a totally different person and he would like start beating on her and stuff. And she was like, if you ever get in an abusive relationship, it's best for you to get out the first time that somebody hits you. And she was like don't be crazy and go back or don't listen to what they say because you can get yourself into a lot of trouble." She went on to comment "It makes me see it a little different ... I mean it makes me want to like, if I do like get in a relationship, I mean I would have to like see how that person is around people". It was these types of stories that, in one way or another, shaped the meanings of good and bad relationships for these girls.

\section{Discussion}

The purpose of this study was to explore the perceptions of African-American adolescent girls about virginity and relationships, and how these perceptions influence their decisions to engage in or abstain from sexual activity. The majority of participants understood being a virgin to mean that they had not engaged in oral, anal, or vaginal sex. However, there were a few participants who believed that having oral and anal sex did not constitute loss of virginity. This ongoing misconception among adolescents about what defines sex is widely reported in the literature. ${ }^{7,18-22}$ Of concern is that this misconception leads adolescents to perceive less risk of contacting a sexually transmitted infection including HIV when they engage in oral and anal sex. Addressing such misconceptions is important for improving adolescent sexual health. Therefore, further research is needed to identify the sources of this misconception.

Being a virgin was highly valued by the majority of participants in the study, and was associated with pride in oneself and self-respect. Although not explicitly discussed, each of the participants described themselves in a positive way, which was evident as they talked about their self-worth in relation to their virginity status. Our findings indicated that it was important to them to maintain their virginity and not give it away to someone who they did not consider to be the "right" person. This is consistent with findings from a qualitative study that explored definitions of loss of virginity among young adults aged 18-35 years. In that study, nearly half of the participants viewed virginity as a treasured possession only to be given to someone worthy of it. ${ }^{18}$ If these views of virginity are common among young adolescent females, an important question is what happens to such views as they become older and become sexually active. A plethora of research has been conducted to identify factors that predict sexual debut. ${ }^{23-28}$ However, research is warranted to understand how adolescents' views of virginity change as they transition to first sexual intercourse. It is important to understand the changes in their views of virginity so that programs designed to delay sexual activity can address these views appropriately.

The participants alluded to their mothers' role in shaping their views about virginity as well as instilling in them a sense of pride and self-respect. Therefore, it is imperative to involve mothers and their daughter in sexual risk reduction programs to promote effective, quality sexual communication. Numerous studies have been conducted to examine and improve sexual communication between mothers and daughters; however, more research is needed to understand the level and type of sexual communication that occurs during early adolescence. Additionally, research is needed to understand the contextual factors that influence the ability of both mother and daughter to communicate openly about topics related to sex.

In regard to the ideal boyfriend, there were common features among the qualities that the participants identified as being important in a boyfriend. Our findings suggest that the participants were looking for a boyfriend who would be supportive of them and their opinions, as well as be concerned with his academic accomplishments. This is consistent with findings from a study on ideal partner selection among adolescents, which showed that adolescents preferred to be in a long-term relationship with a partner who is funny and smart, whereas physical appearance was more important in a short-term or casual relationship. ${ }^{29}$ In our study, adolescent girls valued internal qualities (ie, humor, intelligence) as well as physical appearance. Thinking about internal qualities in a boyfriend provides a foundation for helping adolescent girls to think about the "type" of boy they want to date and how essential they believe it is that he possess the qualities they identify as important. This is a key factor in helping adolescent girls make decisions about whom they will date and with whom they will engage in sexual activity.

Even though the majority of participants did not indicate that they were involved in a romantic relationships, they had specific opinions about the quality of relationship in which they wanted to be involved. Our findings indicate that the 
participants wanted to be in relationships where they feel loved and respected. Additionally, the ability to talk openly with each other about anything was also important because it established a sense of trust and support. Similar findings from other studies show that caring and communication are associated with intimacy and supportiveness. ${ }^{10,30,31}$ Much of the literature on partner selection ${ }^{32-35}$ and relationship quality ${ }^{1,10,36,37}$ focus on older adolescents and adolescent mothers. More research involving early adolescents is needed.

The perception of the participants who believed that a good relationship involves arguing and fighting cannot be overlooked. In further discussion with those participants, it was evident that the majority would provoke an argument with their boyfriend to "test his love". Based on the conversations in that focus group, there was no single role model or factor that helped to shape the participants' views. It appeared to be a compilation of their observations of peers, family, and the media (ie, reality television) where relationship "drama" was a common theme. There is the concern that having such views about relationships are potential precursors to being involved in unhealthy abusive relationships. Therefore, further research is needed in this area.

Through the conversations in the individual interviews and focus groups, it was apparent that the participants' desire to maintain their virginity could be compromised if all the pieces (perceived ideal boyfriend, perceived good relationship) came together. However, true conflict could occur if their idealized views of boyfriends and relationships are not congruent with reality. For example, in terms of social development, adolescent girls tend to seek closeness in relationships whereas adolescent boys tend to avoid intimacy in a relationship. ${ }^{38}$ Similar articles ${ }^{1,10,39,40}$ on romantic relationships among adolescents suggest that boys are often socialized to avoid expressions of tenderness and loving emotions in relationships. Instead they are socialized to view romantic relationships as an opportunity to engage in sexual activity. In contrast, girls are socialized to focus on romance, affection, and caring. ${ }^{39,40}$ When these differing approaches to relationships collide, an important question is how will the adolescent girl reconcile her expectations of a boyfriend and relationship with reality. In such situations, if the adolescent girl lowers her expectations to match reality, there is the potential issue of a power imbalance in the relationship, with the adolescent girl yielding to her partner in order to maintain the relationship. Findings from studies on power imbalance in relationships among young adult women show that women who perceive they have less power in the relationship report lack of ability to negotiate condom use. ${ }^{41-44}$ In terms of the current study, the issue of potential power imbalance raises concern about adolescent girls engaging in high-risk sexual practices, such as inconsistent condom use and multiple sex partners, in order to maintain romantic relationships. Because of the consequences associated with high-risk sexual behavior (ie, pregnancy, sexually transmitted infection, HIV), further research is needed to identify factors associated with power imbalance in adolescent romantic relationships.

Identity is a major developmental task during adolescence. ${ }^{8}$ Because intimacy is closely linked to development of identity, ${ }^{8,9}$ the ability of girls to navigate romantic relationships in early adolescence can potentially influence development of their identity. When adolescents' views related to romantic relationships and intimacy are challenged, there is the potential for them to conform to their partners' desires in order to initiate and/or maintain the relationship. Consequently, their personal identity is suppressed which, if continued over time, can have negative long-term consequences that continue throughout adulthood. ${ }^{2}$ The negative consequences can include low self-esteem, lack of confidence in communicating with a partner, depression, and risk for future negative romantic relationships. ${ }^{1,2,30}$ Therefore, research is warranted to explore the positive and negative influence of romantic relationships on development of identity during early adolescence. It is also important to gain an understanding of the context in which early adolescent girls decide to compromise or maintain their values and beliefs about romantic relationships and intimacy.

When considering the themes identified in this study, the overarching theme becomes "maintaining virginity within the context of good relationship with the ideal boyfriend". It is important to think about how these early adolescent girls will navigate situations in which their views about virginity, boyfriends, and romantic relationships are challenged. It must also be considered that it is within the context of such situations that early adolescent girls are at increased risk of unprotected sexual intercourse. Romantic relationships among early adolescents are understudied. It is imperative that such relationships are further explored in order to inform pregnancy and sexually transmitted infection prevention programs that target young adolescent girls.

A limitation of this study is the possibility that participants provided socially desirable responses. However, to decrease that risk, participants were assured that their responses would be kept confidential and not shared with their parents. Based on the degree of openness in the individual interviews and focus groups, it is believed that the participants were truthful in their responses. Another limitation is the extent to which 
the study findings can be generalized, given that our research was limited to early adolescent African-American girls living in the Southeastern United States. Potential sampling bias is another limitation. To address this issue, every effort was made to ensure that the sample represented a range of socioeconomic backgrounds (based on whether participant received a free or low-cost school lunch, Table 1), ${ }^{17}$ participant education (public, private, city schools), and family structure (one-parent and two-parent households).

\section{Conclusion}

The sociocontextual factors that influence sexual decisionmaking during adolescence are multifaceted and are further complicated by the developmental changes which adolescents undergo. The findings, while limited, provide an insight into how early adolescent African-American girls view being a virgin. Additionally, there is improved knowledge of the interplay of boyfriend and relationship qualities when making decisions about initiating or abstaining from sexual activity, which is important when trying to determine intervention strategies. Findings from this study suggest sexually transmitted infection prevention programs should incorporate activities to enhance values such as self-worth, self-pride, and self-respect, which are likely to play an important role in an adolescent girl's decision to engage in or abstain from sex. Furthermore, our findings suggest the need for education about healthy relationships.

\section{Acknowledgments}

This research was supported by award number K01NR011277 from the National Institute of Nursing Research. The content is solely the responsibility of the authors and does not necessarily represent the official views of the National Institute of Nursing Research or the National Institutes of Health.

\section{Disclosure}

The authors report no conflicts of interest in this work.

\section{References}

1. Collins WA, Welshi DP, Furman W. Adolescent romantic relationships. Апnи Rev Psychol. 2009;60:631-652.

2. Montgomery MJ. Psychosocial intimacy and identity: From early adolescence to emerging adulthood. J Adolesc Res. 2005;20:346-374.

3. Furman W, Shaffer L. The role of romantic relationships in adolescent development. In: Florsheim P, editor. Adolescent Romantic Relations and Sexual Behavior: Theory, Research, and Practical Implications. Mahwah, NJ: Lawrence Erlbaum Associates Publishers; 2003.

4. Meier A, Allen G. Romantic relationships from adolescence to young adulthood: evidence from the National Longitudinal Study of Adolescent Health. Sociol Q. 2009;50:308-335.

5. Piaget J. Intellectual evolution from adolescence to adulthood. Hum Dev. 2008;51:40-47.
6. Yurgelun-Todd D. Emotional and cognitive changes during adolescence. Cur Opin Neurobiol. 2007;17:215-251.

7. Ott MA, Pfeiffer EJ, Fortenberry JD. Perceptions of sexual abstinence among high-risk early and middle adolescents. $J$ Adolesc Health. 2006;39:192-198.

8. Allison BN, Schultz JB. Interpersonal identity formation during early adolescence. Adolescence. 2001;36:509-523.

9. Martyn KK, Hutchinson SA, Martin JH. Lucky girls: unintentional avoidance of adolescent pregnancy among low-income AfricanAmerican females. J Spec Pediatr Nurs. 2002;7:153-161.

10. Giordano PC, Manning WD, Longmore MA. Affairs of the heart: qualities of adolescent romantic relationships and sexual behavior. J Res Adolesc. 2010;20:983-1013.

11. Centers for Disease Control and Prevention. Youth risk behavior surveillance - United States, 2011. MMWR Morb Mortal Wkly Rep. 2012;61:1-162.

12. Aspy CB, Vesely SK, Tolma EL, et al. Youth assets and delayed coitarche across developmental age group. J Early Adolesc. 2010;30: 277-304.

13. Houlihan AE, Gibbons FX, Gerrard M, Yeh H, Reimer RA, Murry VM. Sex and self: the impact of early sexual onset on the self-concept and subsequent risky behavior of African American adolescents. $J$ Early Adolesc. 2008;28:70-91.

14. Long-Middleton ER, Burke PJ, Cahil Lawrence CA, Amudala NH. Understanding motivations for abstinence among adolescent young women: insights into effective sexual risk reduction strategies. J Pediatr Health Care. April 21, 2012. [Epub ahead of print.]

15. Centers for Disease Control and Prevention. Sexually transmitted disease surveillance 2010. 2011. Available from: http://www.cdc.gov/ std/stats. Accessed April 13, 2012.

16. Sandelowski M. Focus on research methods: whatever happened to qualitative description? Res Nurs Health. 2000;23:334-340.

17. US Department of Agriculture. School meals: income eligibility guidelines. 2012. Available from: http://www.fns.usda.gov/cnd/ governance/notices/iegs/iegs.htm. Accessed September 11, 2012.

18. Carpenter LM. The ambiguity of "having sex": The subjective experience of virginity loss in the United States. J Sex Res. 2001;38:127-139.

19. Halpern-Felsher BL, Cornell JL, Kropp RY, Tschann JM. Oral versus vaginal sex among adolescents: perceptions, attitudes, and behavior. Pediatrics. 2005;115:845-851.

20. Remez L. Oral sex among adolescents: is it sex or is it abstinence? Fam Plann Perspect. 2000;32:298-304.

21. Bersamin MM, Fisher DA, Walker KL, Hill DL, Grube JW. Defining virginity and abstinence: adolescents' interpretations of sexual behaviors. J Adolesc Health. 2007;41:182-188.

22. Haglund K. Sexually abstinent African American adolescent females' descriptions of abstinence. J Nurs Scholarsh. 2003;35:231-236.

23. Cavanaugh SE. The sexual debut of girls in early adolescence: the intersection of race, pubertal timing, and friendship group characteristics. J Res Adolesc. 2004;14:285-312.

24. Meier AM. Adolescents' transition to first intercourse, religiosity, and attitudes about sex. Soc Forces. 2003;81:1031-1052.

25. Brewster KL, Tillman KH. Who's doing it? Patterns and predictors of youths' oral sexual experiences. J Adolesc Health. 2008;42:73-80.

26. Buhi ER, Goodson P. Predictors of adolescent sexual behavior and intention: a theory-guided systematic review. J Adolesc Health. 2007;40:4-21.

27. Ompan DC, Strathdee SA, Celentano DD, et al. Predictors of early initiation of vaginal and oral sex among urban young adults in Baltimore, Maryland. Arch Sex Behav. 2006;35:53-65.

28. Lieberman LD. Early predictors of sexual behavior: implications for young adolescents and their parents. Perspect Sex Reprod Health. 2006;38:112-114.

29. Regan PC, Joshi A. Ideal partner preferences among adolescents. Soc Behav Pers. 2003;31:13-20.

30. Collins WA. More than myth: the developmental significance of romantic relationships during adolescence. $J$ Res Adolesc. 2003;13:1-24. 
31. Bralock AR, Koniak-Griffin D. What do sexually active adolescent females say about relationship issues? J Pediatr Nurs. 2009;24: 131-140.

32. Polk S, Ellen JM, Chung S, Huettner S, Jennings JM. Discordance between adolescent real and ideal sex partners and association with sexually transmitted infection risk behaviors. J Adolesc Health. 2011;48: 604-609.

33. Nelson LE, Morrison-Beedy D, Kearney MH, Dozier A. Sexual partner type taxonomy use among urban Black adolescent mothers. Can J Hum Sex. 2011;20:1-10.

34. Nelson LE, Morrison-Beedy D. Sex partner type and condom use in African American adolescent mothers: a literature review. J Child Adolesc Psychiatr Nurs. 2008;21:213-219.

35. Andrinopoulos K, Kerrigan D, Ellen JM. Understanding sex partner selection from the perspective of inner-city Black adolescents. Perspect Sex Reprod Health. 2006;38:132-138.

36. De Goede IHA, Branje S, van Duin J, VanderValk IE, Meeus W. Romantic relationship commitment and its linkages with commitment to parents and friends during adolescence. Soc Dev. 2011:1-18. Advance online publication.

37. Akers A, Yonas M, Burke J, Chang J. "Do you want somebody treating your sister like that?”: Qualitative exploration of how African American families discuss and promote healthy teen dating relationships. $J$ Interpers Violence. 2011;26:2165-2185.
38. Perry DG, Pauletti RE. Gender and adolescent development. J Res Adolesc. 2011;21:61-74.

39. Giordano PC, Manning WD, Longmore MA. Adolescent romantic relationships: an emerging portrait of their nature and developmental significance. In: Crouter AC, Booth A, editors. Romance and Sex in Adolescence and Emerging Adulthood: Risks and Opportunities. Mahwah, NJ: Lawrence Erlbaum Associates Inc; 2008.

40. Shulman S, Scharf M. Adolescent romantic behaviors and perceptions: age- and gender-related differences, and links with family and peer relationships. J Res Adolesc. 2000;10:99-118.

41. Bralock AR, Koniak-Griffin D. Relationship, power, and other influences on self-protective sexual behaviors of African American female adolescents. Health Care Women Int. 2007;28:247-267.

42. Harvey SM, Bird ST. What makes women feel powerful? An exploratory study of relationship power and sexual decision-making with African Americans at risk for HIV/STDS. Women Health. 2004; 39:1-19.

43. Pulerwitz J, Amaro H, De Jong W, Gortmaker SL, Rudd R. Relationship power, condom use and HIV risk among women in the USA. AIDS Care. 2002;14:789-800.

44. Bontempi JMB, Eng E, Quinn SC. Our men are grinding out: qualitative examination of sex imbalances, relationship power, and low-income African American women's health. Women Health. 2008;48:63-81.
Nursing: Research and Reviews

\section{Publish your work in this journal}

Nursing: Research and Reviews is an international, peer-reviewed, open access journal publishing original research, reports, reviews and commentaries on all aspects of nursing and patient care. These include patient education and counselling, ethics, management and organizational issues, diagnostics and prescribing, economics and

\section{Dovepress}

resource management, health outcomes, and improving patient safety in all settings. The manuscript management system is completely online and includes a very quick and fair peer-review system. Visit http://www.dovepress.com/testimonials.php to read real quotes from published authors. 